\title{
Research on the Cultivation of Science and Engineering Students' Entrepreneurship Ability under the Environment of Internet +
}

\author{
Jing Li \\ Nanjing Forestry University, institute of Science \\ Email: lijing1020@163.com
}

\begin{abstract}
With the Chinese economic growth rate of downward pressure, economic growth is going into the highspeed stage, it is showing a new economic normal, but also brought greater pressure to the employment of college students. At the same time, with the continuous development of social economy, science and technology with each passing day, the adjustment of industrial structure changes, it needs a large number of good hands and feet, with innovative entrepreneurial awareness and ability of high-quality compound talents, therefore, it is of great practical significance and long-term strategic significance to promote the scientific development of higher education, deepen the reform of education and teaching and improve the quality of personnel training.
\end{abstract}

Keywords-Internet+; College Student Entrepreneurship Ability; Cultivation Method

\section{INTRODUCTION}

China is from the employment era to the entrepreneurial era youth innovation and entrepreneurship action has become an important driving force for the future economic development of the country. First, science and engineering students as one of the representatives in the country from the traditional industrialization, the process of information technology reflects the unique value of their own innovation and entrepreneurship. And the study of public entrepreneurship is currently emerging in the world and you can for science and engineering students to carry out research to carry out a solid theoretical basis. Second, science and engineering students to carry out entrepreneurial activities, from the national macro level is not only to solve the employment difficulties to maintain social stability needs, but also to cultivate technical talents to achieve national innovation strategy needs. From the internal level of higher education is to enhance the level of entrepreneurship education in colleges and universities to improve the success rate of students the practical needs. Thirdly, how to grasp and guide the students in accordance with their own characteristics, ability and existing basic entrepreneurial ability to prevent the "universalization, one-sidedness" in the situation that the students of science and engineering are increasingly concerned with the government, universities and students', the extreme "entrepreneurial behavior, and the effective conduct of entrepreneurial activities is the current urgent problem to be solved [1].

Entrepreneurship is the basic way to develop the interest of science and engineering college students and realize the ideal of value. Since the reform and opening up, Chinese economic speed has been rapid development, the total economic volume has been greatly improved, has become the world's second largest economic entity, but the overall level of economic development is still very backward, the development is still uneven. At present, Chinese existing industries and jobs can not meet the growing needs of the structural needs of science and engineering talent. We advocate self-entrepreneurship, allowing a part of the overall quality of the higher, comprehensive ability and excellent professional quality of science and engineering students from the traditional posts released, self-personal development, is to give full play to their interests, self-worth and respect for talent the development of the quality of the wise move.

Science and engineering college students have a professional advantage. Science and Engineering is a general term for science and engineering, after graduation in line with the relevant provisions will be awarded a degree in science or engineering degree. Science focuses on theoretical research and scientific exploration, while engineering is more emphasis on technical applications and practical operations. In recent years, the development of science and engineering in China more and more categories, increasingly sophisticated categories, professional development direction of the division is also more and more fine [2], and most of the professional development momentum is more and more strong. In addition, many science and engineering college students during the school is also under the guidance of professional teachers under the guidance of scientific research and practical practice of learning, not only accumulated a wealth of professional theoretical knowledge and practical experience, but also initially mastered some basic operating skills and Professional skills, and even some students also received personal patents or inventions, these achievements constitute the future of their own professional advantages of entrepreneurship.

\section{The CURRENT SituATION OF CULTIVATING INNOVATIVE AND ENTERPRISING ABILITY OF SCIENCE AND ENGINEERING COLLEGE STUDENTS}

Although Chinese education system in the greater efforts of the reform, but the colleges and universities in science and engineering students to innovate the ability to cultivate the means, is still relatively conservative, are generally to listen to lectures, listen to reports, or participate in "business plan contest "and so on, but also for the students to participate in 
entrepreneurial competition also lack the appropriate guidance, or guidance is not enough. Some colleges and universities set up employment guidance courses in the students' innovation and entrepreneurship guidance is not enough, teachers can not keep up with the power. Compared with the traditional higher education, the innovation and entrepreneurship education is more demanding to the teachers. It requires teachers not only to have deep and solid theoretical knowledge, but also to have rich entrepreneurial experience and to meet the requirements of teachers. Colleges and universities in the training process can not practice innovation and skills innovation throughout the main line of student learning, innovation and entrepreneurship ability to cultivate students not enough, so that students only adapt to the traditional teaching that is passive acceptance of the model, which makes the students innovation Entrepreneurial passion is difficult to mobilize.

By the impact of traditional thinking, Chinese college students are generally willing to high income, good location, strong stability of state organs, institutions, large state-owned enterprises and other units, and for science and engineering students, but also by science and engineering thinking, For the regular things are more interested in, like the rules, rigorous way of doing things, not good at dealing with intricate relationships do not like to speculate on people do not want to compromise [3]. Science and engineering students do scientific research, behave, in strict accordance with the rules of service, such a rigorous thinking habit for scientific research is necessary, but if the thinking is too rigid, not enough innovation and innovation courage, it is difficult to push new ideas and promote the progress of science and technology. For the high risk and complexity of the business is difficult, science and engineering college students is even try not to touch, and science and engineering college students in the direction of employment than the liberal arts students more emphasis on professional counterparts, relatively few job competitors, employment pressure without liberal arts students, which also led to science and engineering college students entrepreneurial intention is not so strong liberal arts students. These factors have led to Chinese science and engineering students' generally innovative entrepreneurial awareness is not very strong.

The lack of opportunities for innovation and entrepreneurship of science and engineering college students is related to the degree of emphasis on the cultivation of students' innovation and entrepreneurship ability. This kind of university does not attach importance to this, which leads to the lack of practical support system for the innovation and entrepreneurship ability of science and engineering college students. We pay too much attention to the cultivation of theoretical and academic talents which make students lose a lot of innovation despite the solid theoretical knowledge Entrepreneurial opportunities. And colleges and universities in the school-enterprise cooperation is more concerned about the transformation of scientific research and technology or to solve the problem of student employment, for students to business exchange practice to improve students' ability to innovate and do not pay much attention, but also lead to science and engineering students innovative business opportunities to reduce. Second, because science and engineering college students generally more academic than the liberal arts students, the course content is difficult, more time for post-class exercises, and teachers for students of the school and research requirements more stringent, for students achievements and scientific research more attention, science and engineering students need to spend more time than liberal arts students in the study and research, which also led to science and engineering students do not have spare time to participate in innovation and entrepreneurship practice.

\section{MAINTAINING THE INNOVATIVE AND ENTERPRISING ABILITY OF SCIENCE AND ENGINEERING COLLEGE STUDENTS}

First of all, the education sector and the managers of colleges and universities should recognize the important role of innovation and entrepreneurship ability in personnel training, improve the degree of attention to the cultivation of innovation and entrepreneurship ability of science and engineering students, and make substantial contributions from teachers, funds, venues and policies Sexual support. Secondly, colleges and universities in the training plan to consciously plan to integrate into the innovation and entrepreneurship ability of college students to strengthen the links, strengthen the science and engineering college students innovation and entrepreneurship instructor team building. In addition, to establish a specialized entrepreneurial education team to absorb a group of specialized business theory research background, the relevant entrepreneurial experience of teachers as a leader in college entrepreneurship education, but also part-time teachers to employ some experienced success of the enterprise Home, entrepreneur as supplement [4].

At the same time, for professional teachers must also be required in the teaching process, into the innovation and entrepreneurship ability to cultivate awareness education. The impact of professional teachers on students is straightforward and profound. Their orientation and requirements determine the direction of development of students. If the teachers in the course of teaching encourage students to innovate and even guide students to discover their own business opportunities in their professional research field encourage them to put into practice, for students to innovate and cultivate the ability to play a multiplier role. For example, in the Sichuan University School of chemistry last year, three students started and registered companies and there are two students in the professional teachers under the guidance of the establishment of professional-related companies.

Aiming at the lack of quality of science and engineering college students' innovation and entrepreneurship, colleges and universities should formulate corresponding solutions. In order to solve the problem of establishing a unified and scientific curriculum system, we can set up a few core courses, innovation and entrepreneurial ideas and awareness, as well as to teach entrepreneurship financing, entrepreneurial risk and entrepreneurial practice of knowledge, to strengthen the science and engineering college students in the law, management and other aspects of knowledge training, encourage students to choose some professional knowledge courses, Social science knowledge of learning and accumulation. In addition, students can also encourage interdisciplinary, in particular, and liberal arts students to form 
innovation and entrepreneurship team, learn from each other, the formation of complementary effects. But also strengthen the science students' hard-working, perseverance, not afraid of failure and courage to challenge the spirit of training. Through these methods, we help science and engineering college students to improve the quality of innovation and entrepreneurship.

Colleges and universities should cope with the practice of innovation and entrepreneurship of science and engineering college students to increase the policy tilt, to provide more opportunities for innovation and entrepreneurship practice. Such as actively promoting the "college students innovation and entrepreneurship program" "college students entrepreneurial competition", college students' incubator base construction. Encourage teachers to attract more students to participate in their research, in improving the level of professional knowledge at the same time, improve the sense of innovation and entrepreneurship, but also in the professional learning process to find business opportunities. But also to establish the characteristics of science and engineering college students innovation and entrepreneurship club, into the entrepreneurial incubator [5], so that students with interest and professional expertise as the basis, to independent research, hands-on practice, the use of professional laboratories set up a small production line, the student's creativity into the product In the training of students innovative entrepreneurial awareness and practical ability. It is the requirement of the development of knowledge economy and the requirement of promoting social development and progress. It is also the requirement of realizing the great "Chinese dream" of our country, and grasping the characteristics of science and engineering college students themselves and strengthening their innovation and entrepreneurship ability. On the basis of professional education, to change the educational ideas, update the concept of education as the guide to enhance students' sense of social responsibility, innovation, entrepreneurial awareness and entrepreneurial ability as the core, to reform the talent training model and curriculum system to focus on strengthening innovation Entrepreneurial practice as the starting point, through this series of effective ways to vigorously promote the college students of science and engineering innovation and entrepreneurship education, and constantly improve the quality of science and engineering college students training.

Curriculum reform carries out entrepreneurship teaching induction. This is the current practice of entrepreneurship education theory is more practical than the specific measures. Teaching induction requires teachers to accept and adopt new teaching methods, in the entrepreneurial teaching activities for science and engineering college students can use task-driven and typical demonstration of teaching methods to induce students to spontaneously generate entrepreneurial perspectives to consolidate entrepreneurial enthusiasm to develop entrepreneurial capacity. In the task-driven link teachers to science and technology entrepreneurial activities of the technical points and difficulties set specific tasks, requiring students to complete the task in groups and according to the group to complete the task of the process and results to give comments and scoring, which induced the students' enthusiasm for competition and teamwork awareness, in the process of completing the task to obtain professional knowledge and experience. In the typical demonstration link teachers introduce technical entrepreneurs or enterprises in the research and development of the person in charge of the school, the practical and operational teaching content to teach. These entrepreneurs are the successful example of real entrepreneurship, and entrepreneurial interaction can be induced in the emotional enthusiasm of students, effectively stimulate students 'imitation consciousness, to consolidate students' interest in entrepreneurship and enhance the degree of entrepreneurship education. In order to enhance the effect of teaching induction can be considered in the organizational structure of the adjustment, the establishment of a dedicated business center or entrepreneurial college and the current University of the prevalence of technological innovation center, product development center and employment consulting machine to carry out cooperation, to play these organizations of entrepreneurship education and counseling. For example, by the Entrepreneurship Center is responsible for providing entrepreneurial courses $\mathrm{R} \& \mathrm{D}$ resources, through cooperation with the transformation of science and technology departments and engineering and technology-related industries and academic links between the release of innovative business research topics. But also with the school employment advisory body, from the industry and career development prospects for students to start business consulting and practice platform services to enhance students' entrepreneurial confidence.

Integration of disciplines create innovative entrepreneurial atmosphere. In order to solve the practical problems of the lack of connection between teachers, disciplines and professional training in colleges and universities, colleges and universities should create an open and tolerant atmosphere that is conducive to the students' interest in hobbies or their talents. At home and abroad a large number of mature business areas such as Guigu Valley, Zhongguancun and other places to prove that an active and focused entrepreneurial atmosphere in cultivating entrepreneurial spirit to stimulate college students play a pivotal role in entrepreneurship. In the organization actively encourage students to set up a variety of science and technology business community, such as geeks) clubs, innovators salon, science and business exchanges, virtual entrepreneurship workshops. For example, the establishment of scientific and commercial communication organizations can allow students of science and engineering students' access to business knowledge and skills, access to these knowledge and skills in the relaxed atmosphere with the business students to get, no classroom teaching pressure is more acceptable for students. In the activities can take advantage of spare time will be interested in science and technology entrepreneurs gathered together to organize a variety of sharing sessions, exhibitions, luncheon and other experience activities. These organizations to carry out entrepreneurial activities or projects help to promote science and engineering college students' entrepreneur team building and operational capacity of the formation. In the education management can refer to the successful experience of some foreign universities to reform, in the school system and the management of school students can be more flexible liberation of interested students. Ministry of Education issued on the date of "on the national average college graduates employment notice" provides that colleges and universities 
should be developed for all college students to set up innovative entrepreneurship education courses and into the credit management; colleges and universities to establish a flexible academic system allow students to leave school. Colleges and universities can be based on their own conditions in the Ministry of Education on the basis of the documentary school with the economic and social conditions to do further exploration.

Material incentives set up Entrepreneurship grants. Set up dedicated business incentives to help funds can greatly stimulate students to participate in entrepreneurial education initiative. School set up entrepreneurship scholarships can take the way of school-enterprise cooperation, the introduction of local high-tech enterprise funds as entrepreneurial students to help the funds. The funds can set the agreed incentive conditions, such as encouraging or giving priority to support students to carry out technical entrepreneurial activities, the funds do not account for the shares of students to start the enterprise, do not participate in dividends, students operating in a certain period of time after the return of business performance or part of the total funding. The incentive role of the scholarship is to expand the trend: through the successful declaration of entrepreneurial funds students' sense of accomplishment was inspired, the establishment of the company to carry out technical activities based on the entrepreneurial activities are also motivating the followers of imitation; the introduction of local science and technology enterprises to provide funding Support can improve the level of local school-enterprise combination, but also can stimulate the students to get a sense of technology and regional sense of belonging. Entrepreneurial scholarship incentives need to assess the size of the objective and scientific assessment, the school should be adjusted according to the actual situation, at any time may be concerned about the potential incentive to reduce the marginal benefits of the problem.

Department of co - operation starts a business start - up system. Multi - type, the integration of the curriculum system is the core of science and engineering students' entrepreneurial ability training. This is because the integration of the curriculum system can open up science and engineering, management, humanities and arts disciplines of professional wall fish, through the diversification of education to effectively enhance the entrepreneurial skills and entrepreneurial management capabilities. In the establishment of entrepreneurial capacity training courses should be considered fully learn from the international advanced experience. Take the example of the United States and once again to view Stanford University: Stanford University Business School at the end of the year first set up entrepreneurship education courses, entered the Stanford University Institute of Technology began to implement entrepreneurship education, and achieved outstanding results. In view of the technical entrepreneurs are complex high-level talent characteristics, Stanford University Institute of Technology attaches great importance to the interdisciplinary education of entrepreneurship. To this end, the school actively promotes cooperation with the school business school to seek resource sharing and complementary advantages. In the full development of entrepreneurial science and technology capacity training courses at the same time in the curriculum to insist on entrepreneurship education and general education, humanities education and science education combined to achieve entrepreneurial spirit and entrepreneurial management capacity at the same time follow. The Stanford Technology Venture Project Team is a department of management science and engineering at Stanford University's Faculty of Engineering (one of the objectives of the project team is to promote high-tech entrepreneurship research. Stanford University Institute of Technology to rely on entrepreneurship education teaching, research and cooperation at home and abroad, its development The University of Berkeley is committed to establishing a connection with a nearby large enterprise company to enable schools, students, enterprises, and business schools to work together. The University of Berkeley is committed to establishing a network of entrepreneurial education programs in science and engineering colleges, which is widely accepted and imitated in the world. The San Francisco-One Palo Alto Scientific Industrial Complex is the largest regional science industrial complex on the west coast of the United States, with its main technology and talent relying on the University of Berkeley. The University of Berkeley School is characterized by high-tech entrepreneurship for this purpose, Berkeley College of Technology collaborates with business schools to select hightech projects into all of the school's global enterprise laboratories for incubation.

\section{CONCLUSION}

It is not only an important measure to reduce the employment pressure of college students and maintain social stability, but also to enhance the objective demand of national innovation and competitiveness. Science and engineering subjects reflect the development of industrial and social science and technology direction, is an important part of advanced productive forces, is an important driving force for social and economic development. Therefore, the cultivation of entrepreneurial ability of science and engineering students should pay enough attention, entrepreneurship education and entrepreneurial practice should be the whole society, all levels of government departments or institutions of the safe implementation.

\section{REFERENCES}

[1] Lu Jun. The key to the implementation of the pioneering plan for college students is to improve the success rate of entrepreneurship [J]. Ideological and theoretical education. 2014 (10).

[2] He Jianhua, Ding Donghong. Study on the Application of Case Method in Chinese Entrepreneurship Research [J]. Science and Technology Progress and Countermeasures. 2014 (05).

[3] Ma Hongjia, Dong Baobao, Ge Baoshan. Research on the Relationship between Entrepreneurial Capability, Dynamic Capability and Enterprise Competitive Advantage [J]. Journal of Scientific Research. 2014 (03).

[4] Lin Jian. Research on the Implementation of "Excellent Engineer Education and Training Program" in Colleges and Universities[J]. Ideological and theoretical education. 2012 (06).

[5] Lin Jian.; Research on the Implementation of the "Excellent Engineer Education and Training Program[J]. Journal of Scientific Research. 2006 (08). 